\title{
One-pot synthesis of $\mathrm{CpMo}(\mathrm{CO})_{3} \mathrm{Cl}$
}

\section{Introduction}

This method of making $\mathrm{CoMo}(\mathrm{CO})_{3} \mathrm{Cl}$ puts together several useful syntheses of various intermediates into a one-pot procedure which we don't think has been published in the literature as such. Probably the closest thing is a paper by Hoffmann ${ }^{1}$ which gives a one-pot synthesis of the analogous tungsten complex, though it uses the tris-acetonitrile tricarbonyl complex as an intermediate (which ours doesn't).

1. Hoffmann, N.W. Inorg. Chim. Acta 1984, 88, 59-61.

\section{Things you'll need}

Sodium metal

Toluene, distilled from sodium or sodium/benzophenone (or suitably purified, e.g Grubbs solvent system).

THF, also freshly distilled from sodium or sodium/benzophenone.

Dicyclopentadiene

Iron filings

Molybdenum hexacarbonyl

Glacial acetic acid

Carbon tetrachloride

Dichloromethane and petroleum ether or hexane for column chromatography.

\section{WARNING!}

A good fume hood must be used. Molybdenum hexacarbonyl is very toxic and relatively volatile: wear gloves and weigh it out in the hood. Dicyclopentadiene has an irritating odour and should be considered as toxic, as should cyclopentadiene itself. Sodium is corrosive and will react violently with water to give hydrogen gas, which then often catches fire - make sure you know how to handle and get rid of sodium safely before you start this prep! Glacial acetic acid is corrosive, and carbon tetrachloride is a known carcinogen.

\section{Preliminary}

The first thing you will need to prepare is a cyclopentadiene still. Place about $150 \mathrm{~mL}$ of commercial dicyclopentadiene into a one neck, $250 \mathrm{~mL}$ round bottom flask and add about $0.5 \mathrm{~g}$ of iron filings. Stick a $30 \mathrm{~cm}$ Vigreux column in the top of it, and in the top of that put a typical distillation set-up: still head with thermometer, condenser, receiving flask. Preferably include some sort of nitrogen inlet so that the whole thing can be run under an inert atmosphere. For space saving reasons we actually use a set-up in which the still head and the nitrogen inlet are next to each other, with the condenser situated vertically (parallel to the Vigreux column) with the receiving flask on the end. One final thing: be prepared to write off the flask and the Vigreux column. You can keep topping the still up and distilling cyclopentadiene from it but after a while you'll find that it becomes impossible to release the column from the flask. Occasionally the dicyclopentadiene polymerises, in which case you have to throw the flask away, though to be fair we haven't had this happen for years now. 


\section{Part 1: Making sodium cyclopentadienide}

The reaction is carried out in a two- or three necked $250 \mathrm{~mL}$ round bottom flask fitted with a condenser. The top of the condenser is fitted with an adapter to connect to a nitrogen or argon supply, as is one of the side necks of the flask. Make sure all your condenser tubes are properly secured as the reaction has to reflux overnight a bit later. Evacuate the flask and back-fill it with nitrogen or argon; make sure in all the subsequent steps you keep a good flow of inert gas coming out of the flask whenever you add reagents.

The first stage is to make sodium sand. Place $0.55 \mathrm{~g}$ of sodium metal in the flask, and add a stirrer bar and about $100 \mathrm{~mL}$ of distilled toluene. Heat the flask with a heating mantle until the toluene refluxes and the sodium melts, stirring all the time. There are two key features to making a good sodium sand, and the first is sufficiently rapid stirring - you need a really good vortex in the centre of your flask. You'll find that after about half an hour of refluxing and stirring the sodium will have broken up into very small globules - the smaller the better. Now comes the second key step: turn the mantle off and quickly lift the flask out of it (get someone else to help you move the mantle out of the way if necessary). The reason this bit is so important is that it means that the flask cools rapidly and the sodium solidifies before it has chance to recoagulate into one big globule: if you just turn the mantle off and leave the flask in there to cool down, you'll find that all you get is your original lump of sodium back again, albeit a bit more shiny-looking.

Cool the flask down to room temperature. While that is happening, start up your cyclopentadiene still. You will need to put it on a pretty high mantle setting, as dicyclopentadiene boils at about $170^{\circ} \mathrm{C}$, but halfway up the Vigreux column the dimer undergoes a retro-Diels Alder reaction to give the monomer, which is pretty low-boiling. Consequently the temperature on the thermometer at the top of your column shouldn't get higher than about $44^{\circ} \mathrm{C}$. The monomer collects in the receiving vessel as a colourless, very smelly liquid. It shouldn't take very long to collect the amount needed for the reaction. It is stable for a couple of hours or so, but eventually redimerises, so if you're going to keep it any longer than that, cool it in ice or put it in a flask in the freezer.

When the reaction flask has cooled completely, replace the condenser in the central neck by a stopper and then syringe off the toluene and discard it - careful you don't syringe up any bits of sodium too! Then add about $20 \mathrm{~mL}$ of freshly distilled THF, swill it round for a few minutes, and then syringe off the THF and discard that as well. Then add about a further $125 \mathrm{~mL}$ of THF. Place the flask on a flat bed stirrer. You should now have your sodium sand suspended in THF. If it's fizzing away merrily, that means that your THF isn't dry enough, by the way.

Place a pressure equalising dropping funnel into the central neck of the flask. At this point you can evacuate and back-fill with nitrogen again to make sure there's no air present. Cool the flask in ice. Add $8 \mathrm{~mL}$ of the cracked cyclopentadiene monomer to the dropping funnel, and then add this dropwise to the stirred cold sodium sand suspension over a period of about 20 minutes to half an hour. You'll see that the shiny little globules go almost black - don't worry about it. If you stop the stirrer for a minute you'll also see a fair amount of fizzing going on as hydrogen is evolved. After all the cyclopentadiene has been added, carry on stirring the cooled flask for about an hour and then take it out of the ice bath and stir until all the sodium has reacted. Depending on how good your sodium sand is, this can take anything from a total reaction time of a couple of hours to 4 or more hours, which is why it's worth getting your sand right in the first place. Depending on how good your THF or your nitrogen supply is, 
you may also notice the gradual development of a pink colour to the solution: this is one of the decomposition products of $\mathrm{NaCp}$, and as long as it doesn't get too bad, don't worry about it. By too bad, I mean that pink will be OK, burgundy is OK-ish and brown to black is no good. If all your sodium doesn't react, the only thing you can do is add some more cyclopentadiene; however the $8 \mathrm{~mL}$ we use is a vast excess and we've never had that problem.

\section{Part 2: Making $\mathrm{Na}\left[\mathrm{Mo}(\mathrm{CO})_{3} \mathrm{Cp}\right]$}

You now have a THF solution of NaCp. In the fume cupboard, weigh out $5.8 \mathrm{~g}$ of molybdenum hexacarbonyl and add it to the reaction flask (use a powder funnel to stop getting it all over the ground glass joint). Then reattach the condenser, take away the flat-bed stirrer and put the flask back in the heating mantle. Heat the solution to reflux overnight for about 19 hours. Before it gets to reflux you'll see plenty of bubbling going on as the reaction starts and $\mathrm{CO}$ is evolved. If you start the prep in the morning, you should get to this point well before 5 o'clock so you can leave it overnight.

\section{Part 3: Making $\mathrm{CpMo}(\mathrm{CO})_{3} \mathrm{H}$}

By the following morning, the solution should have turned to a yellow or orange colour. Turn off the heating and allow the reaction to cool to room temperature, then replace the condenser with a stopper or better still, a SubaSeal. Add $7.8 \mathrm{~mL}$ of glacial acetic acid to the solution with a syringe. It will lighten slightly and go somewhat cloudy as if there is something in suspension. Stir for 45 minutes.

\section{Part 4: Making $\mathrm{CpMo}(\mathrm{CO})_{3} \mathrm{Cl}$}

Use a syringe again to add $7 \mathrm{~mL}$ of carbon tetrachloride dropwise through the SubaSeal. As you add it, the yellow-orange cloudy suspension will turn rapidly into a dark orange-red solution. Stir for 2 hours.

\section{Part 5: Work-up}

Remover the solvent on a vacuum line (N.B. probably best not to use a rotary evaporator as there may still be some carbon tetrachloride present). Dissolve the red residue in dichloromethane and filter through a sintered glass funnel to remove the insoluble precipitate of sodium acetate. Add a few grams of silica and remove the solvent on a rotary evaporator. Load the residue onto a silica chromatography column made up in petroleum ether (or its equivalent such as hexane etc.). Elute with a mixture of 10$20 \%$ dichloromethane in pet ether to remove a pink-purple band of $\mathrm{Mo}_{2}(\mathrm{CO})_{6} \mathrm{Cp}_{2}$ - there shouldn't be much of this, and it usually isn't worth collecting. Then gradually increase the proportion of dichloromethane. With about 50-75\% dichloromethane you should obtain a large orange red band of the product. A typical yield is $4.9 \mathrm{~g}$ or about $80 \%$. Its solution IR spectrum in dichloromethane shows peaks at 2055 (strong) and 1797 (strong and broad) $\mathrm{cm}^{-1}$. The product is reasonably air stable, but if you store it for a while even in a closed vial it will gradually turn green; all is not lost though, because it will still dissolve up red, and a quick recolumn will get back most of your compound. If you store it for a couple of years, it doesn't dissolve up red any more and then it's time to throw it away!

(C) 2004-6 M.J. Morris 